\title{
Differentiation of the Stereochemistry and Anomeric Configuration for 1-3 Linked Disaccharides Via Tandem Mass Spectrometry and ${ }^{18}$ O-labeling
}

\author{
Chiharu Konda, ${ }^{1}$ Brad Bendiak, ${ }^{2}$ Yu Xia ${ }^{1}$ \\ ${ }^{1}$ Department of Chemistry, Purdue University, West Lafayette, IN 47907-1393, USA \\ ${ }^{2}$ Department of Cell and Developmental Biology, and Program in Structural Biology and Biophysics, University of Colorado \\ Denver, Anschutz Medical Campus, Aurora, CO, USA
}

\begin{abstract}
Collision-induced dissociation (CID) of deprotonated hexose-containing disaccharides $(\mathrm{m} / \mathrm{z} 341)$ with 1-2, 1-4, and 1-6 linkages yields product ions at $m / z 221$, which have been identified as glycosyl-glycolaldehyde anions. From disaccharides with these linkages, CID of $\mathrm{m} / z 221$ ions produces distinct fragmentation patterns that enable the stereochemistries and anomeric configurations of the non-reducing sugar units to be determined. However, only trace quantities of $m / z 221$ ions can be generated for 1-3 linkages in Paul or linear ion traps, preventing further CID analysis. Here we demonstrate that high intensities of $\mathrm{m} / \mathrm{z} 221$ ions can be built up in the linear ion trap (Q3) from beam-type CID of a series of 1-3 linked disaccharides conducted on a triple quadrupole/linear ion trap mass spectrometer. ${ }^{18} \mathrm{O}$-labeling at the carbonyl position of the reducing sugar allowed mass-discrimination of the "sidedness" of dissociation events to either side of the glycosidic linkage. Under relatively low energy beam-type CID and ion trap CID, an $\mathrm{m} / \mathrm{z} 223$ product ion containing ${ }^{18} \mathrm{O}$ predominated. It was a structural isomer that fragmented quite differently than the glycosylglycolaldehydes and did not provide structural information about the non-reducing sugar. Under higher collision energy beam-type CID conditions, the formation of $\mathrm{m} / \mathrm{z} 221$ ions, which have the glycosyl-glycolaldehyde structures, were favored. Characteristic fragmentation patterns were observed for each $\mathrm{m} / \mathrm{z} 221$ ion from higher energy beam-type CID of 1-3 linked disaccharides and the stereochemistry of the non-reducing sugar, together with the anomeric configuration, were successfully identified both with and without ${ }^{18} \mathrm{O}$-labeling of the reducing sugar carbonyl group.
\end{abstract}

Key words: Oligosaccharides, Stereochemistry, Anomeric configuration, Collision-induced dissociation, Tandem mass spectrometry

\section{Introduction}

$\mathrm{C}$ arbohydrates play important roles in biological systems, such as providing energy to cells and functioning as

Electronic supplementary material The online version of this article (doi:10.1007/s13361-011-0287-5) contains supplementary material, which is available to authorized users.

Correspondence to: Yu Xia; e-mail: yxia@purdue.edu structural components for plant cell walls. By conjugating with proteins and lipids, carbohydrates are widely involved in cell-cell interactions, cell signaling, and self and non-self recognition events $[1,2]$. Carbohydrates can form almost unlimited variations in their structures due to their structural complexity. In order to elucidate the structure of an oligosaccharide, it is necessary to characterize the stereochemistry of each monosaccharide unit, the anomeric configuration of the glycosidic bonds, linkage positions, 
and the sequence of the individual monosaccharides in the oligomer. When enough sample is available, higherdimensional NMR is a powerful tool to obtain detailed structural information [3-5].

Mass spectrometry is a widely applied method in structural analysis of carbohydrates, due to its capability of providing detailed molecular information and high sensitivity [6]. The molecular weight information of carbohydrates is readily obtained from soft ionization methods such as electrospray ionization (ESI) $[7,8]$ and matrix-assisted laser desorption/ionization (MALDI) [911]. Tandem mass spectrometry based on collisioninduced dissociation (CID) is heavily relied on to obtain structural information for carbohydrates. Glycosidic bond cleavages and/or cross-ring cleavages are typically observed from collisional activation. Following the nomenclature proposed by Domon and Costello , A, B, and C ions are fragments containing the non-reducing terminus while $\mathrm{X}, \mathrm{Y}$, and $\mathrm{Z}$ ions include the reducing end [12]. Four types of fragments, B, C, Y, and $\mathrm{Z}$ ions, are formed from cleavages on either side of the glycosidic oxygen. $\mathrm{B}$ and $\mathrm{Y}$ ions are cleaved at the non-reducing side of a glycosidic oxygen and $\mathrm{C}$ and $\mathrm{Z}$ ions are cleaved at the reducing side of a glycosidic oxygen. Based on the specific mass differences of fragments resulting from glycosidic bond cleavages, sequence information for both linear and branching oligosaccharides as well as glycotypes such as the complex, hybrid, or high-mannose can be determined for methylated oligosaccharides $[8,13]$.

$\mathrm{A}$ and $\mathrm{X}$ ions result from cross-ring cleavages and they are typically more informative for the structural analysis of carbohydrates. It has been shown that the relative abundances of these ions can be correlated to the linkage position, and in some cases, the anomeric configuration and stereochemistry of each monosaccharide. For example, CID spectra of deprotonated di- and oligosaccharide alkoxy anions in the negative ion mode showed distinguishable fragmentation patterns for each linkage position, which was successfully applied to di-, tri-, and hexasaccharides [1417]. Negative ion adducts $[18,19]$ and positive adducts $[20$, 21] of deprotonated di- and oligosaccharides have also enabled linkage positions to be determined, both in the negative and positive ion modes, and linkage sites can be established for neutral disaccharides as positive ion adducts of lithium or sodium ions or as protonated adducts [22-27]. Determination of anomeric configuration has been demonstrated for underivatized disaccharides in the negative ion mode $[15,17,18]$, for derivatized 1-4- and 1-6-linked disaccharides [28], and in the positive ion mode with alkali metals [22-27] and lead cationization [20]. Prior knowledge such as linkage position, ring form, and stereochemistry [15, $17,18,20,22-28]$, however, was typically required to assign anomeric configuration, which was difficult to apply to larger oligosaccharide systems [18]. CID of metal cationized monosaccharides derivatized as a Schiff base with diethylenetriamine [29] and CID of metal cationized $N$ acetylhexosamine diastereomers [30] have been shown to produce distinct fragmentation patterns according to the stereochemistry. The assignment of stereochemistry has also been obtained by matching the CID spectrum of acetylated monosaccharides in oligosaccharides with reference spectra $[31,32]$. Using additional statistical analysis, anomeric configuration has been identified for metal cationized glucopyranosyl-glucose disaccharides $(1-2,-3,-4$, and -6 linkages) [26]. Also, the linkage positions and stereochemistries of non-reducing units can be discriminated for glucose, galactose, and mannose containing disaccharides having $1-2,-3$, and -4 linkages [27].

Recently, a tandem mass spectrometry approach has been developed to differentiate the stereochemistry and anomeric configuration for the non-reducing unit of hexose-containing disaccharides having any of the 16 possible stereochemical variants [33, 34]. In this method, diagnostic ions at $\mathrm{m} / \mathrm{z} 221$ were formed from CID of deprotonated disaccharide ions $(\mathrm{m} / \mathrm{z}$ 341). It was established that the $m / z 221$ ions consisted of the intact non-reducing sugar glycosidically linked to glycolaldehyde, as indicated in Scheme 1 (where GA abbreviates glycolaldehyde). Note that an open-chain form for the reducing sugar is indicated in Scheme 1 and also for other disaccharides discussed later. This is based on the observation of absorbance in the carbonyl stretch region in variable wavelength infrared radiation photo-dissociation of deprotonated monosaccharide anions in the gas phase [35].

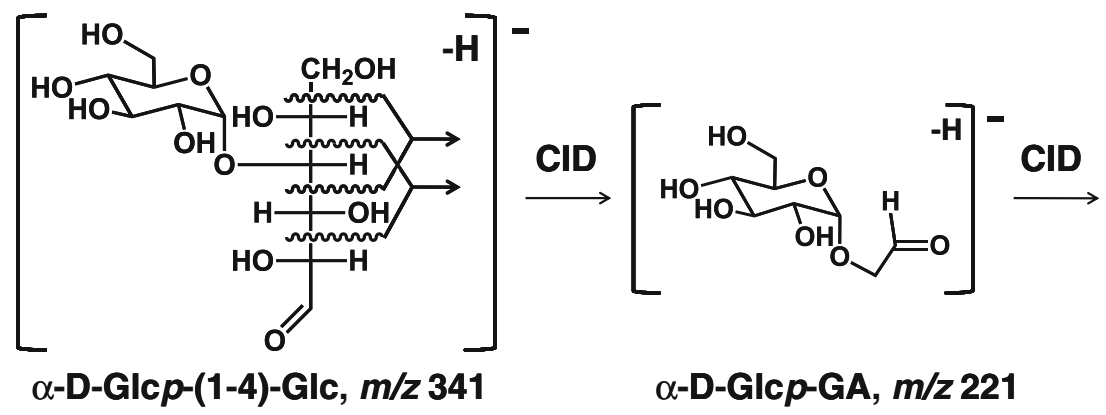

Scheme 1. Formation of glycosyl-GA anions at $m / z 221$ from CID of deprotonated 1-4 linked disaccharides 
When $m / z 221$ ions were further dissociated by collisional activation, disaccharides having different non-reducing sugar units and anomeric configurations showed distinct fragmentation patterns that matched synthetic glycosyl-GAs. This method was shown to be useful for assigning the stereochemistry as well as the anomeric configuration of the glycosidic bond for the non-reducing sugar in disaccharides having $1-2,1-4$, and $1-6$ linkages $[33,34]$. However, due to the low abundance of $\mathrm{m} / \mathrm{z} 221$ ions produced from 1-3 linked disaccharides, $\mathrm{MS}^{3} \mathrm{CID}$ of $\mathrm{m} / z 221$ ions could not be performed, and it was unclear whether the fragmentation patterns could be used for assigning either their stereochemistry or anomeric configuration.

Herein, a series of 1-3 linked disaccharides were studied on a triple quadrupole-linear ion trap mass spectrometer (QTRAP 4000). $\mathrm{MS}^{3} \mathrm{CID}$ data of $m / z 221$ ions from the 1-3 linked disaccharides were obtained for the first time. The formation of $\mathrm{m} / \mathrm{z} 221$ ions was examined using different collisional activation methods, i.e., beam-type CID and ion trap CID of the deprotonated disaccharides. ${ }^{18} \mathrm{O}$-labeling of the reducing carbonyl oxygen in 1-3 linked disaccharides was used to enable mass-discrimination of structural isomers of the (usually) $\mathrm{m} / \mathrm{z} 221$ ions. By choosing the proper CID conditions, the diagnostic $\mathrm{m} / \mathrm{z} 221$ ions (the glycosyl-GAs) could be formed as the dominant isomer. Their CID fragmentation patterns could be used to establish the stereochemistry and anomeric configuration of the nonreducing sugar unit from 1-3 linked disaccharides.

\section{Experimental}

\section{Materials}

$\alpha$-D-Glc $p$-(1-2)-D-Glc (kojibiose), $\beta$-D-Glc $p$-(1-2)-D-Glc (sophorose), $\alpha$-D-Glc $p$-(1-3)-D-Glc (nigerose), $\alpha$-D-Glcp(1-3)-D-Fru (turanose), and $\mathrm{H}_{2}{ }^{18} \mathrm{O}$ were purchased from Sigma-Aldrich, Inc. (St. Louis, MO, USA); $\beta$-D-Glcp-(1-3)D-Glc (laminaribiose), $\alpha$-D-Man $p$-(1-3)-D-Man (3 $\alpha$-manno-

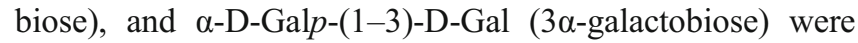
purchased from Carbosynth, Ltd. (Berkshire, UK). $\alpha$ - and $\beta$ monosaccharide-glycolaldehyde standards, glucopyranosylglycolaldehydes (Glcp-GA), galactopyranosyl-glycolaldehydes (Galp-GA), and mannopyranosyl-glycolaldehydes (ManpGA) were synthesized as previously described [33]. Disaccharides and synthetic standards were dissolved in methanol to a final concentration of $0.01 \mathrm{mg} / \mathrm{mL}$ and $\mathrm{NH}_{4} \mathrm{OH}$ was added to a final concentration of $1 \%$ immediately before use.

\section{${ }^{18}$ O-Labeling of Reducing Disaccharides}

Disaccharides $\left(1 \mathrm{mg}\right.$ ) were dissolved in $100 \mu \mathrm{L}$ of $\mathrm{H}_{2}{ }^{18} \mathrm{O}$ for 3 to $10 \mathrm{~d}$ at room temperature. The solution was further diluted to $0.1 \mathrm{mg} / \mathrm{mL}$ with methanol before mass spectrometric analysis.

\section{Mass Spectrometry}

All samples were analyzed in the negative-ion mode on a QTRAP 4000 mass spectrometer (Applied Biosystems/ SCIEX, Toronto, Canada) equipped with a home-built nanoelectrospray ionization (nanoESI) source. A schematic presentation of the instrument ion optics is shown in the Supporting Information, Figure S1. Two types of low energy collisional activation methods were accessible on this instrument, i.e., beam-type CID and ion trap CID. In beam-type CID, the precursor ions $(\mathrm{m} / \mathrm{z} 341$ or 343$)$ were isolated in Q1, accelerated in the Q2 collision cell for collisional activation, and all products were analyzed in the Q3 linear ion trap. Collision energy (CE) was defined by the potential difference (absolute value) between Q0 and Q2. In ion trap CID, the precursor ions were isolated in the Q3 linear ion trap via the RF/DC mode and a dipolar excitation was used for collisional activation. In order to perform ion trap CID at different Mathieu q-parameters, an AC (alternating current) generated from an external waveform generator (Agilent Technologies, Santa Clara, CA, USA) was used for resonance excitation. Frequency and the low mass cut-off were calculated by SxStability (Pan Galactic Scientific, Omemee, Ontario, Canada). MS ${ }^{3}$ CID experiments were carried out by first performing beam-type CID of precursor ions in Q2. The fragment ions of interest were isolated in Q3 and then subjected to ion trap CID. Analyst 1.5 software was used for instrument control, data acquisition, and processing. The typical parameters of the mass spectrometer used in this study were set as follows: spray voltage, -1.1 to $-1.5 \mathrm{kV}$; curtain gas, 10 ; declustering potential, $50 \mathrm{~V}$; beam-type CID collision energy (CE), 5 to $30 \mathrm{~V}$; ion trap CID activation energy (AF2), 5 to 60 (arbitrary units); scan rate, $1000 \mathrm{~m} / \mathrm{z}$; pressure in Q2, $5.0 \times$ $10^{-3}$ Torr, and in Q3, $2.5 \times 10^{-5}$ Torr. Ion injection time was controlled to keep a similar parent ion intensity: typically $3 \times$ $10^{6}$ counts per second (cps) for $\mathrm{MS}^{2} \mathrm{CID}$ experiments and $1 \times 10^{6} \mathrm{cps}$ for $\mathrm{MS}^{3} \mathrm{CID}$ experiments. Activation time was kept constant at $200 \mathrm{~ms}$ for all ion trap CID experiments. Seven spectra were collected for CID of $\mathrm{m} / z 221$ ions from synthesized monosaccharide-GA standards (deprotonated molecules) and disaccharides over a 1 y period. Standard deviations of peak heights were calculated for major fragments such as $m / z 87,99,101,113,129,131,159,161,203$, and 221, which were observed from all the standards and disaccharides studied here except $\beta$-D-Glc $p$-GA and $\beta$-DGlcp-(1-2)-D-Glc, which showed no peaks at $m / z 99$.

\section{Results and Discussion}

Ion trap CID of deprotonated 1-3 linked disaccharides $(\mathrm{m} / \mathrm{z}$ 341) typically generates ions at $m / z 221$ in trace abundance on a Paul trap instrument, and isolation or further CID of $\mathrm{m} / \mathrm{z}$ 221 ions have not been achieved before $[14,15,34,36]$. The 4000QTRAP mass spectrometer used in this study has a unique triple quadrupole-linear ion trap configuration, 
offering high sensitivity due to the large capacity of the linear ion trap, and allowing either beam-type or ion trap collisional activation. In beam-type CID, the precursor ions were isolated in Q1 and accelerated in Q2 for collisional activation, while ion trap CID was conducted in Q3 with a dipolar excitation for collisional activation. Since CID fragmentation patterns can be sensitive to the means of activation, the formation of $\mathrm{m} / \mathrm{z} 221$ ions from five 1-3 linked disaccharides was investigated via both beam-type and ion trap CID. Figure 1 compares the $\mathrm{MS}^{2}$ beam-type and ion trap CID of deprotonated $\beta$-D-Glc $p$-(1-3)-D-Glc $(\mathrm{m} / \mathrm{z}$ 341) using low energy CID conditions. A relatively low CE $(6 \mathrm{~V})$ was used for beam-type CID; in ion trap CID, the AF2 for an AC dipolar excitation was set to 25 (arbitrary units) for $200 \mathrm{~ms}$. Under either activation condition, the absolute
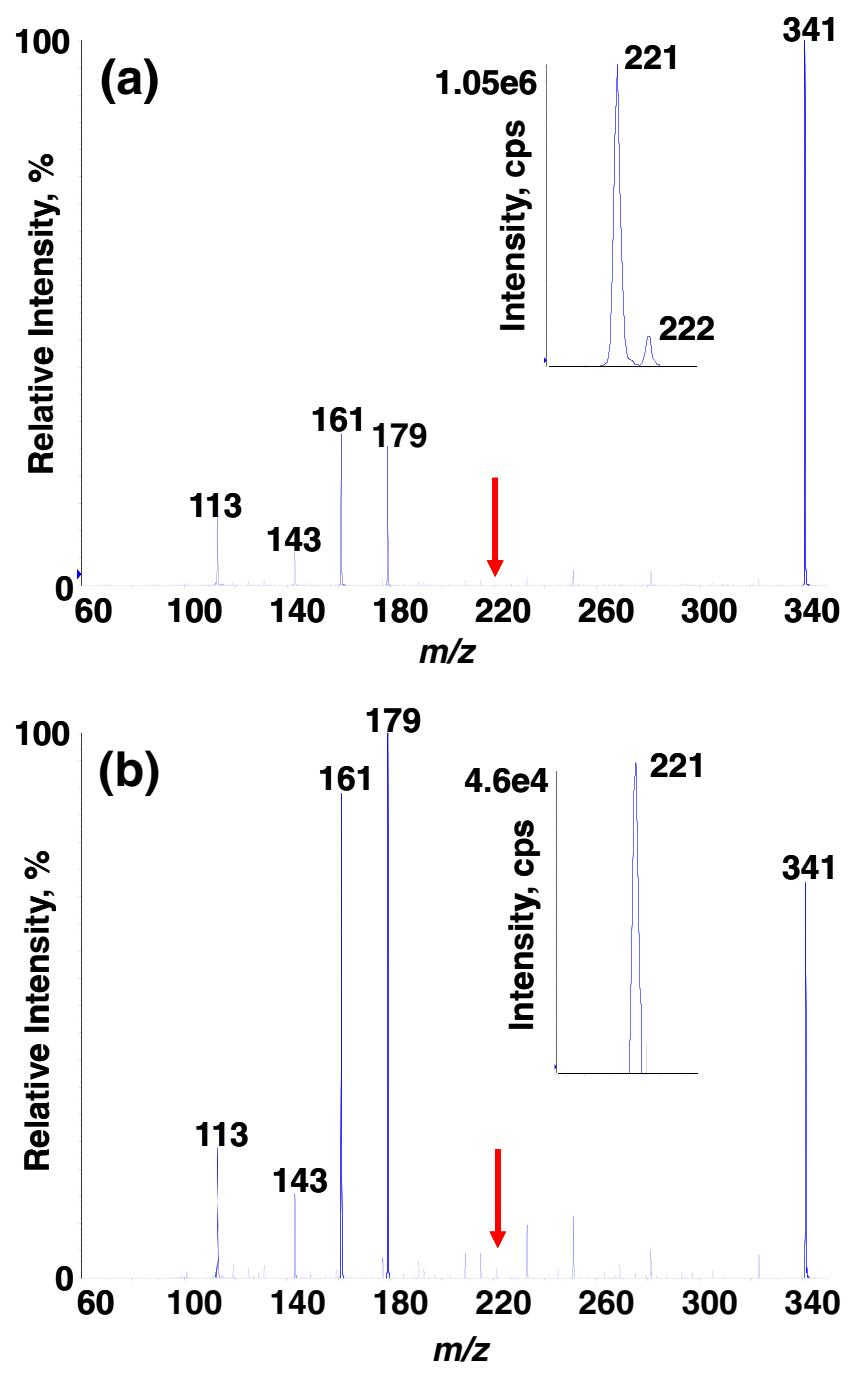

Figure 1. $M S^{2} \mathrm{CID}$ spectra in the negative ion mode obtained from deprotonated $\beta$-D-Glcp-(1-3)-D-Glc ( $m / z$ 341) under low energy dissociation conditions: (a) beam-type CID $(\mathrm{CE}=6 \mathrm{~V})$, and (b) ion trap $\mathrm{CID}(\mathrm{AF2}=25)$. Insets in (a) and (b) show the isolation of $\mathrm{m} / \mathrm{z} 221$ ions generated from beam-type CID (injection time $=1 \mathrm{~s}$ ) and ion trap CID (injection time $=2 \mathrm{~s}$ ), respectively intensities of $\mathrm{m} / \mathrm{z} 221$ ions (indicated by an arrow in Figure 1) were very low and their relative intensities were less than $1 \%$ (normalized to the base peak in the spectrum). This phenomenon was generally observed for all 1-3 linked disaccharides studied herein. The insets in Figure 1 demonstrate the isolated $\mathrm{m} / \mathrm{z} 221$ ions (with a $2 \mathrm{~m} / \mathrm{z}$ isolation window) from each set of dissociation conditions. For beamtype CID, $1 \times 10^{6} \mathrm{cps}$ of $\mathrm{m} / \mathrm{z} 221$ ions could be accumulated with an injection time of $1 \mathrm{~s}$, which was sufficient for performing the next stage of tandem mass spectrometry $\left(\mathrm{MS}^{3}\right.$ in this case) with reasonable ion statistics and sensitivity. Far lower abundance of the $\mathrm{m} / \mathrm{z} 221$ ions (4.6× $10^{4} \mathrm{cps}$ ) could be isolated from ion trap CID of $\mathrm{m} / \mathrm{z} 341$, even after doubling the injection time to $2 \mathrm{~s}$. As a result, it was not feasible to obtain $\mathrm{MS}^{3} \mathrm{CID}$ for $\mathrm{m} / \mathrm{z} 221$ ions generated from $\mathrm{m} / \mathrm{z} 341$ precursor ions initially isolated within the trap. In experiments described below, beam-type CID was used to dissociate disaccharide precursor anions in the Q2 collision cell thereby generating $\mathrm{m} / \mathrm{z} 221$ product ions in high enough abundance to acquire their spectra in the linear trap reproducibly.

\section{CID of m/z 221 Ions Generated from 1-3 Linked Disaccharides}

Previous studies have demonstrated that $\mathrm{m} / \mathrm{z} 221$ product ions formed from collisional activation of disaccharide anions typically consist of an intact non-reducing sugar with a 2-carbon aglycone derived from the reducing sugar [34]. Three dominant fragment peaks are commonly observed from CID of $\mathrm{m} / \mathrm{z}$ 221: $\mathrm{m} / \mathrm{z} 101,131$, and 161 . The relative intensities of these peaks, together with some other fragment ions, can be used to establish the fragmentation patterns and to distinguish the stereochemistry and anomeric configuration of the non-reducing sugar. Given that the CID patterns of $m / z 221$ ions will be used for structural identification, spectral reproducibility is an important issue. Similar to the findings from a Paul trap instrument [33,34], we noticed that the number of ions $(\mathrm{m} / \mathrm{z} 221)$ in the linear ion trap and the energy input into an ion were among the most important parameters affecting spectral reproducibility. To ensure reasonable ion statistics and avoid adverse space charge effects, the intensity of the $\mathrm{m} / \mathrm{z} 221$ ions was kept at $1 \times$ $10^{6} \mathrm{cps}$ before $\mathrm{MS}^{3} \mathrm{CID}$. Based on previous studies, the CID energies were tuned so that the ratio of remaining precursor ion to the most abundant product ion was kept around $18 \% \pm$ $3 \%$ [33]. Figure 2a, b, e, and $\mathrm{f}$ were the averaged spectra from seven repetitions collected over a $1 \mathrm{y}$ period, and they were further used to make spectral comparisons in later discussion. Error bars in the spectra indicate the standard deviation of the peak intensity for 10 major fragment ions, which were frequently observed for all the disaccharides studied herein $(\mathrm{m} / \mathrm{z}$ 87, 99, 101, 113, 129, 131, 159, 161, 203 , and 221). The standard deviations for these peaks were less than $5 \%$ in most cases, indicating high reproducibility of the spectra from day to day by controlling the ion counts in 

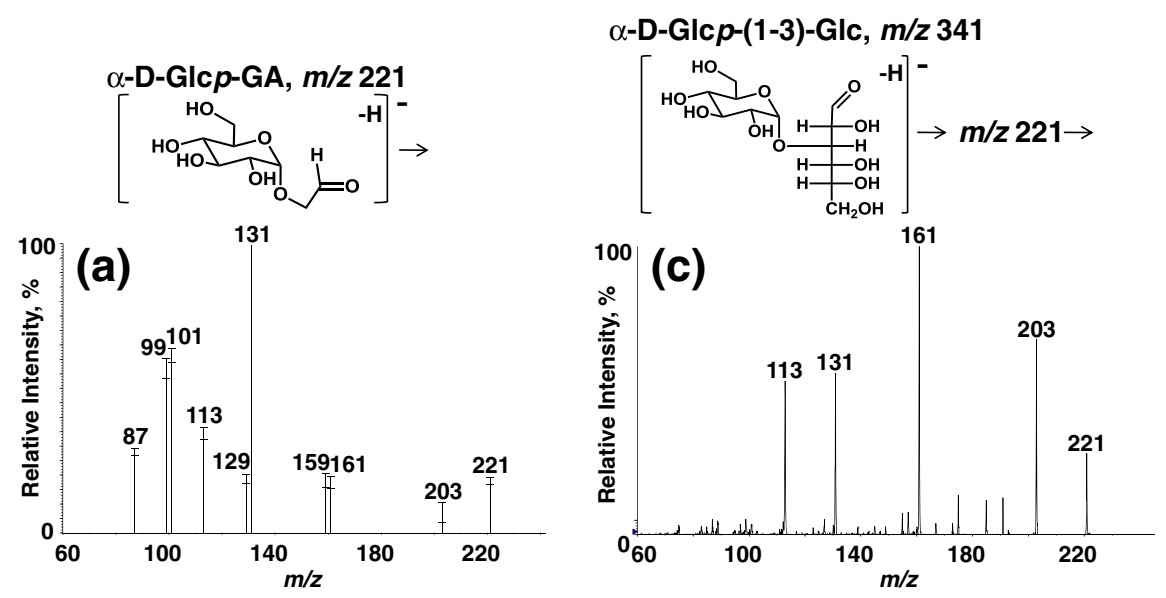

$\beta$-D-GIcp-(1-3)-GIc, $m / z 341$

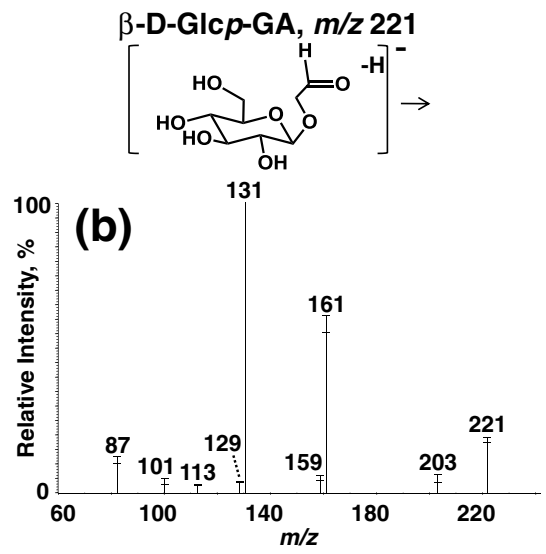

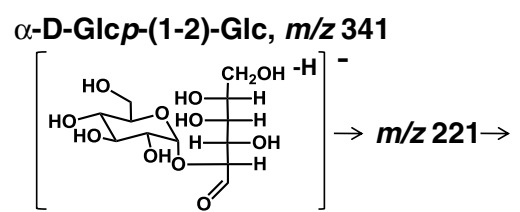
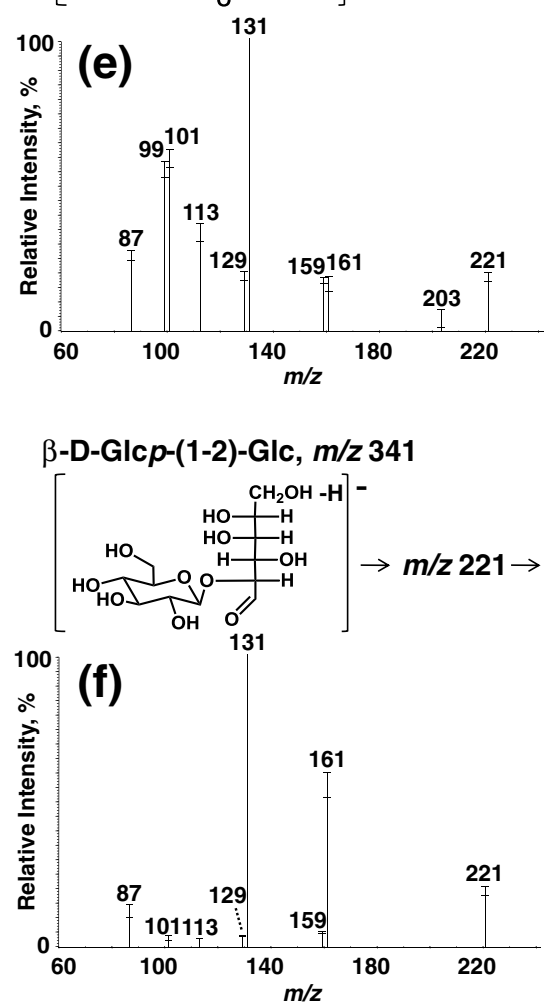

Figure 2. $\mathrm{MS}^{2}$ ion trap CID spectra of $\mathrm{m} / \mathrm{z} 221$ ions derived from synthetic standards (a) $\alpha-D-G l c p-G A, A F 2=25$ and (b) $\beta$-DGlcp-GA, AF2 $=18 . \mathrm{MS}^{3}$ CID spectra of $\mathrm{m} / \mathrm{z} 221$ ions derived from low energy beam-type CID of glucose-containing disaccharides: (c) $\alpha-D-G l c p-(1-3)-G l c, C E=6 \vee$ for $M^{2}$ and $A F 2=25$ for $M S^{3}$, (d) $\beta$-D-Glcp-(1-3)-Glc, CE $=6 \vee$ for $M^{2}$ and $A F 2=25$ for $M^{3}$, (e) $\alpha$-D-Glcp-(1-2)-Glc, CE=5 V for $\mathrm{MS}^{2}$, and $A F 2=27$ for $\mathrm{MS}^{3}$, and (f) $\beta$-D-Glcp-(1-2)-Glc, CE= $5 \mathrm{~V}$ for $\mathrm{MS}^{2}$, and $\mathrm{AF} 2=25$ for $\mathrm{MS}^{3}$. The error bars in the spectra show the standard deviation of the peak intensity based on seven spectra collected over a 1 y period

the trap before CID and the energy input to the ions. Since the CID patterns upon dissociation of $\mathrm{m} / \mathrm{z} 221$ ions can differ to some extent from instrument to instrument [37], CID spectra of the synthetic monosaccharide-GA were collected as standards for comparisons. Figure $2 \mathrm{a}$ and $\mathrm{b}$ show the CID data of $\alpha$ - and $\beta$-D-Glc $p$-GA, respectively. The abundant peaks at $m / z 101$ and 131 in Figure 2a are a signature of a non-reducing glucose with an $\alpha$ anomeric configuration. Note that a distinct fragmentation pattern is observed for the $\beta$ configuration (Figure $2 b$ ), where $m / z 131$ and 161 ions are dominant. The same collisional activation conditions were applied to $m / z 221$ ions derived from $\alpha$-D-Glcp-(1-3)-D-Glc and $\beta$-D-Glc $p$-(1-3)-D-Glc, anomeric isomers containing a non-reducing glucose. It is obvious that the spectra from the two anomeric isomers (Figure $2 \mathrm{c}$ and d) were drastically different from their corresponding D-Glc $p$-GA standards, however, were similar to each other. This indicates that the $\mathrm{m} / \mathrm{z} 221$ ions generated using low collision energies from $\mathrm{m} / \mathrm{z}$ 341 precursors have different structures from the D-Glcp-GA standards, and that their CID patterns cannot be used to assign either the stereochemistry or anomeric configurations of the ions. Note that beam-type CID was used to generate the $\mathrm{m} / \mathrm{z}$ 221 ions from disaccharides shown in Figure 2, a condition differing from previous studies where ion trap CID had been used [33]. This difference in activation could have contributed to the formation of structural isomers observed for the $\mathrm{m} / \mathrm{z} 221$ product ions. In order to test this hypothesis, $m / z 221$ ions of 1-2 linked disaccharides, $\alpha$-D-Glcp-(1-2)-D-Glc and $\beta-\mathrm{D}-$ Glcp-(1-2)-D-Glc, were formed using similar beam-type CID conditions and further subjected to $\mathrm{MS}^{3} \mathrm{CID}$ (Figure 2e and f). Except for a larger fluctuation in peak intensity for $\mathrm{m} / \mathrm{z}$ 203, almost identical fragmentation patterns to the standards were observed (compare Figure 2a to e and $\mathrm{b}$ to $\mathrm{f}$ ), strongly indicating that the expected D-Glcp-GA structures were formed. We further investigated a wide variety of disaccharides and found that the CID patterns of $\mathrm{m} / z 221$ ions matched with their corresponding monosaccharide-GA standards with the exception of 1-3 linked disaccharides when low collision energy beam-type CID conditions were used to dissociate the disaccharides. 
${ }^{18} \mathrm{O}$-labeling at the carbonyl position of the reducing sugar was used to mass-discriminate the "sidedness" of dissociation events to either side of the glycosidic linkage and thus the origins of the $\mathrm{m} / \mathrm{z} 221$ and/or potential 223 product ions. Figure 3 compares relatively low energy beamtype and ion trap CID of ${ }^{18} \mathrm{O}$-labeled deprotonated $\alpha$-DGlcp-(1-3)-D-Glc, $m / z$ 343. Similar fragments were observed for both conditions; however, the ion abundance for $m / z 283$ (loss of $60 \mathrm{Da}, \mathrm{C}_{2} \mathrm{H}_{4} \mathrm{O}_{2}$ ) was much higher in beamtype CID relative to ion trap CID. It is possible that this fragmentation channel requires higher activation energy and is promoted, even in lower-energy beam-type CID, since higher collision energies (several $\mathrm{eV}$ ) may have been obtained as compared to ion trap CID (hundreds of meV).
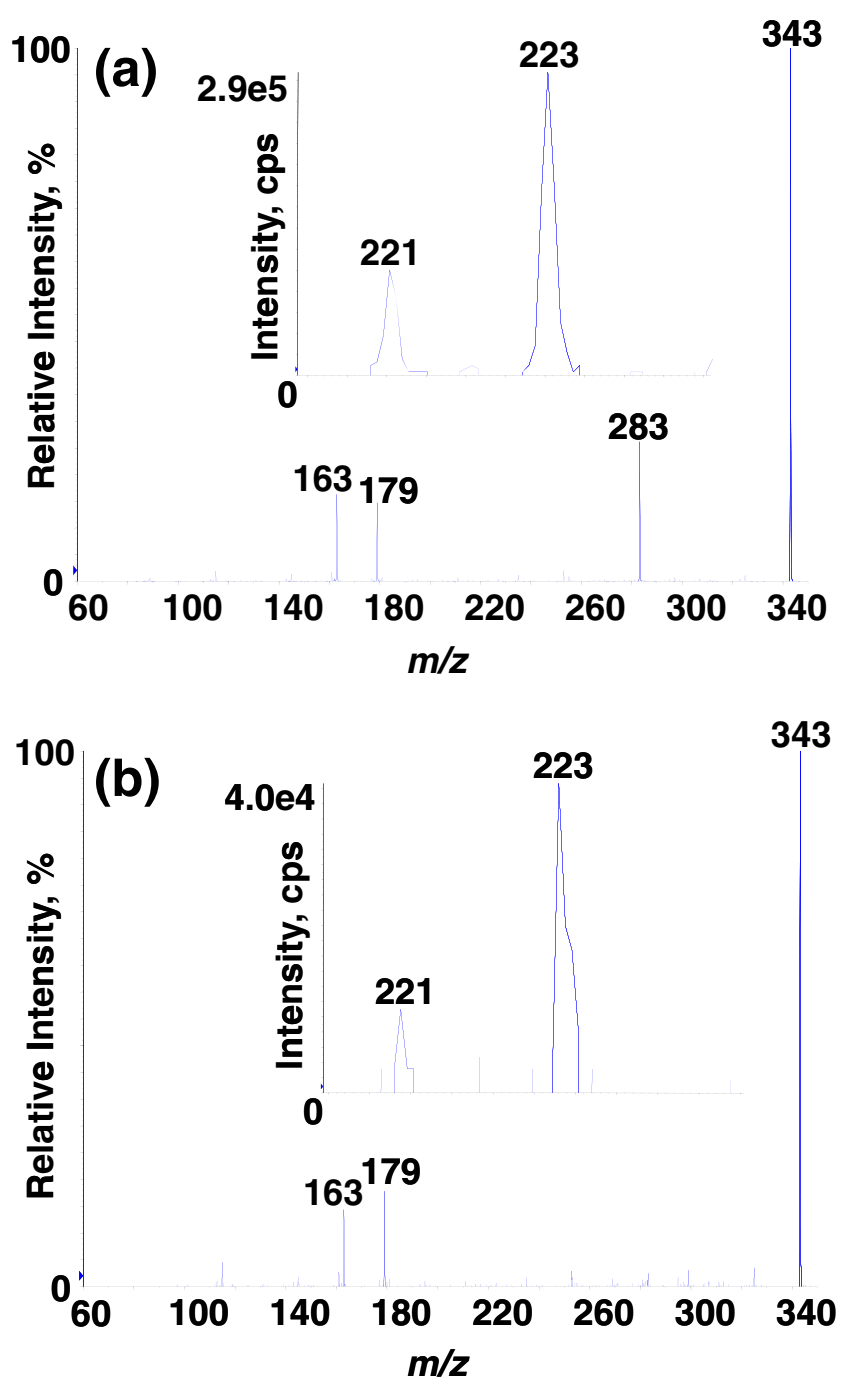

Figure 3. $\mathrm{MS}^{2}$ spectra of ${ }^{18} \mathrm{O}$-labeled $\alpha-D-G l c p-(1-3)-D-G l c$ under (a) relatively low-energy beam-type $\mathrm{CID}(\mathrm{CE}=6 \mathrm{~V})$, and (b) ion trap CID (AF2=25). Insets in (a) and (b) show isolation of $\mathrm{m} / \mathrm{z} 221$ and 223 ions generated from beam-type CID (injection time $=1 \mathrm{~s}$ ) and ion trap CID (injection time $=2 \mathrm{~s}$ ), respectively
The inset in Figure 3a shows data collected using a wide isolation window $(6 \mathrm{~m} / \mathrm{z}$ units) around $\mathrm{m} / \mathrm{z} 221$ after CID of $\mathrm{m} / \mathrm{z} 343$ precursor ions. A peak at $\mathrm{m} / \mathrm{z} 223$, due to incorporation of ${ }^{18} \mathrm{O}$, appeared with much higher abundance than $\mathrm{m} / \mathrm{z} 221$ ions for both low-energy beam-type and ion trap CID. Note that if the expected D-Glcp-GA structure were formed, it should consist of the intact non-reducing sugar unit with a 2-carbon aglycon derived from the reducing sugar (C-2 and $\mathrm{C}-3$ or $\mathrm{C}-3$ and $\mathrm{C}-4)$. In this case, ${ }^{18} \mathrm{O}$ should not be incorporated into the product ion and it should still appear at $\mathrm{m} / z 221$. Therefore, the observation of abundant $\mathrm{m} / \mathrm{z} 223$ ions indicated that under relatively low energy CID conditions, most of the $\mathrm{m} / \mathrm{z} 221$ ions formed from $\alpha-\mathrm{D}-\mathrm{Glc} p-(1-3)-\mathrm{D}-\mathrm{Glc}$ do not have the DGlcp-GA structure which is the structural isomer needed to distinguish the stereochemistry and anomeric configuration of the non-reducing sugar.

Ions at $\mathrm{m} / \mathrm{z} 221$ and $\mathrm{m} / \mathrm{z} 223$ were further subjected to ion trap CID. Figure 4 compares the CID spectra of the isolated $\mathrm{m} / \mathrm{z} 221$ ions and the $\mathrm{m} / \mathrm{z} 223$ ions generated from ${ }^{18} \mathrm{O}-$ labeled $\alpha$-D-Glc $p$-(1-3)-D-Glc and $\beta$-D-Glc $p$-(1-3)-D-Glc. The CID spectra of the $m / z 221$ ions (Figure $4 \mathrm{a}$ and c) from the two anomeric isomers are distinct from each other and almost identical to those of the corresponding $\alpha$ and $\beta$-DGlc $p$-GA standards (Figure 2a and b). The fragmentation patterns of $m / z 223$ (Figure $4 \mathrm{~b}$ and d), however, were similar to each other yet were very different from the synthetic glucosyl-GA standards.

The major fragments that resulted from CID of the $\mathrm{m} / \mathrm{z}$ 223 ions included product ions at $\mathrm{m} / \mathrm{z} 205,163,131$, and 113. These ions are likely due to losses of water $(-18 \mathrm{Da})$, a 2-carbon piece, $\mathrm{C}_{2} \mathrm{H}_{4} \mathrm{O}_{2}(-60 \mathrm{Da})$, a 3-carbon piece including ${ }^{18} \mathrm{O}, \mathrm{C}_{3} \mathrm{H}_{6} \mathrm{O}_{2}+{ }^{18} \mathrm{O}(-92 \mathrm{Da})$, and sequential or concerted losses of a three-carbon piece plus water including ${ }^{18} \mathrm{O}(-110 \mathrm{Da})$, respectively. Interestingly, neither the loss of water nor the loss of 60 Da significantly involves loss of the ${ }^{18} \mathrm{O}$ oxygen. The $\mathrm{m} / \mathrm{z} 223$ ions are hypothesized to have a structure in which the reducing sugar is connected to a two-carbon piece from the non-reducing sugar as shown in the scheme above Figure $4 \mathrm{~b}$ and d. Note that $\mathrm{C}-1$ is no longer chiral on the piece from the (former) non-reducing sugar, which also explains the similarity in the CID data of the $\mathrm{m} / \mathrm{z} 223$ ion derived from the two anomeric isomers (Figure $4 \mathrm{~b}$ and $\mathrm{d}$ ). We also noticed some subtle differences between Figure $4 \mathrm{~b}$ and $\mathrm{d}$. For example, the relative intensities of $\mathrm{m} / \mathrm{z} 205$ and 159 are higher (more than 10\%) in Figure $4 \mathrm{~b}$ than in d. These differences may be due to the existence of a small fraction of structural isomers other than that hypothesized for the $m / z 223$ ions.

\section{The Effect of CID Conditions on the Formation of $\mathrm{m} / \mathrm{z}$ 221/223 Product Ions from 3-Linked} Disaccharides and their ${ }^{18} \mathrm{O}$-Labeled Isotopomers

As demonstrated in Figure 4, abundant structural isomers of $\mathrm{m} / \mathrm{z} 221$ product ions, $\left(\mathrm{m} / \mathrm{z} 223\right.$ ions from the ${ }^{18} \mathrm{O}$-labeled 

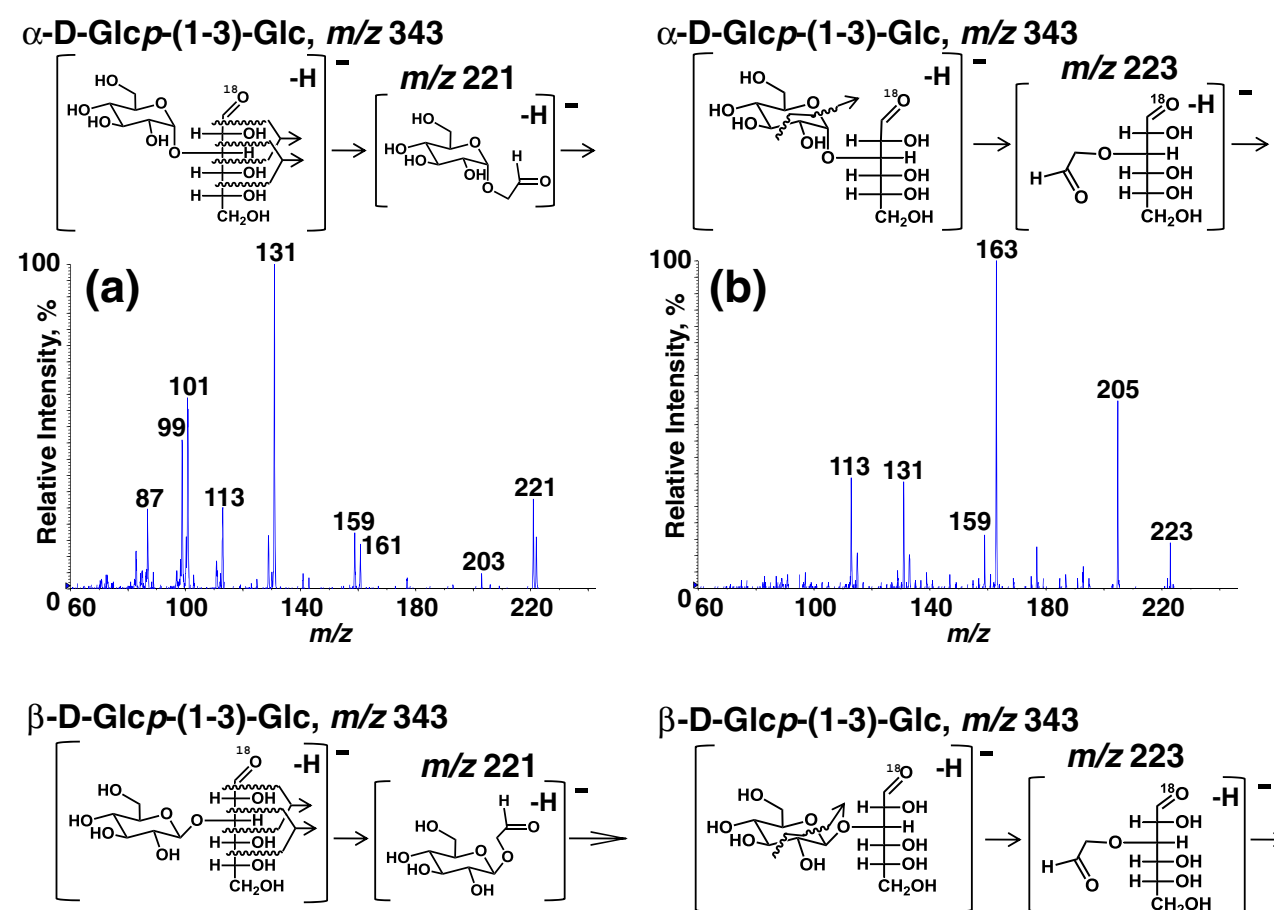

\section{$\beta$-D-GIcp-(1-3)-GIc, $m / z 343$}

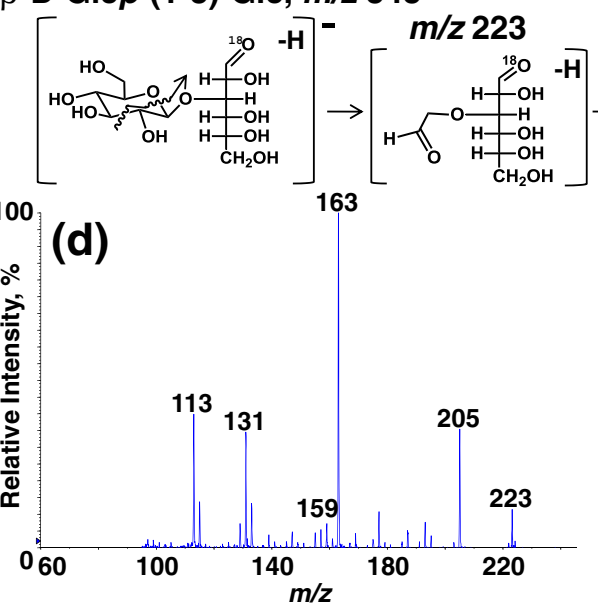

Figure 4. $\mathrm{MS}^{3}$ spectra of $\mathrm{m} / \mathrm{z} 221$ and 223 ions derived from ${ }^{18} \mathrm{O}-$ labeled $\alpha-D-G l c p-(1-3)-D-G l c$ and $\beta$-D-Glcp-(1-3)-D-Glc. (a) $\mathrm{CID}$ of $m / z 221$ ions, $\mathrm{CE}=15 \mathrm{~V}\left(\mathrm{MS}^{2}\right), \mathrm{AF} 2=15\left(\mathrm{MS}^{3}\right)$, (b) CID of $\mathrm{m} / \mathrm{z} 223$ ions, $\mathrm{CE}=5 \mathrm{~V}\left(\mathrm{MS}^{2}\right), A F 2=14\left(\mathrm{MS}^{3}\right)$ from ${ }^{18} \mathrm{O}$-labeled $\alpha-$ D-Glcp-(1-3)-D-Glc, and (c) CID of $m / z 221$ ions, $C E=15 \vee\left(M^{2}\right), A F 2=28\left(M^{3}\right)$, (d) $C I D$ of $m / z 223$ ions, $C E=5 \vee\left(M S^{2}\right), A F 2=$ $24\left(\mathrm{MS}^{3}\right)$ from ${ }^{18} \mathrm{O}$-labeled $\beta$-D-Glcp-(1-3)-D-Glc

disaccharides) were observed under relatively low-energy dissociation conditions of 1-3 linked disaccharides, either using beam-type or ion trap CID. This prevents the assignment of the stereochemistry or anomeric configuration of the non-reducing sugar in a typical scenario where either a disaccharide is unlabeled or when it is isolated (unlabeled) from a larger oligosaccharide structure. It would be highly desirable to optimize CID conditions or, for that matter, to find any dissociation conditions whereby the relatively pure, structurally informative glycosyl-GA $(\mathrm{m} / \mathrm{z} 221)$ ions could be formed predominantly. Figure 5 shows the effect of collision energies on the formation of $\mathrm{m} / \mathrm{z} 221$ and 223 ions under beam-type and ion-trap CID, using ${ }^{18} \mathrm{O}$-labeled $\beta$-DGlcp-(1-3)-D-Glc as an example. The data were collected using a wide isolation window around $\mathrm{m} / \mathrm{z} 221$ to observe both $\mathrm{m} / \mathrm{z} 221$ and 223 ions.

It is clear from Figure 5a-c that the collision energy in beam-type CID affects the absolute and relative intensities of $\mathrm{m} / \mathrm{z} 221$ ions. When the $\mathrm{CE}$ was relatively low $(\mathrm{CE}=5 \mathrm{~V}), \mathrm{m} / \mathrm{z}$ 223 ions were predominantly formed, with four times higher intensity than that of $m / z 221$. At a higher $\mathrm{CE}(\mathrm{CE}=10 \mathrm{~V}), \mathrm{m} / \mathrm{z}$ 221 and 223 ions were seen at nearly equal intensities. Once the $\mathrm{CE}$ was increased to $15 \mathrm{~V}, \mathrm{~m} / \mathrm{z} 221$ ions became the dominant peak, accounting for $80 \%$ of the total intensities from $\mathrm{m} / \mathrm{z} 221$ and 223. Further increasing CE, however, resulted in a huge loss of ion abundance possibly due to competitive ion ejection thus the ratio was not improved.

Parameters that might affect the formation of $\mathrm{m} / \mathrm{z} 221$ ions versus $m / z 223$ ions were also examined for ion trap CID. When ion trap CID of $\mathrm{m} / \mathrm{z} 343$ was performed under the instrument default Mathieu q-parameter ( $\mathrm{q}=0.235), \mathrm{m} / \mathrm{z} 223$ ions were formed exclusively independent of activation energies (data not shown). By changing the activation Mathieu q-parameter to a higher value, precursor ions are placed under a higher potential well depth, and higher activation energies can be applied. An AC generated from an external waveform 

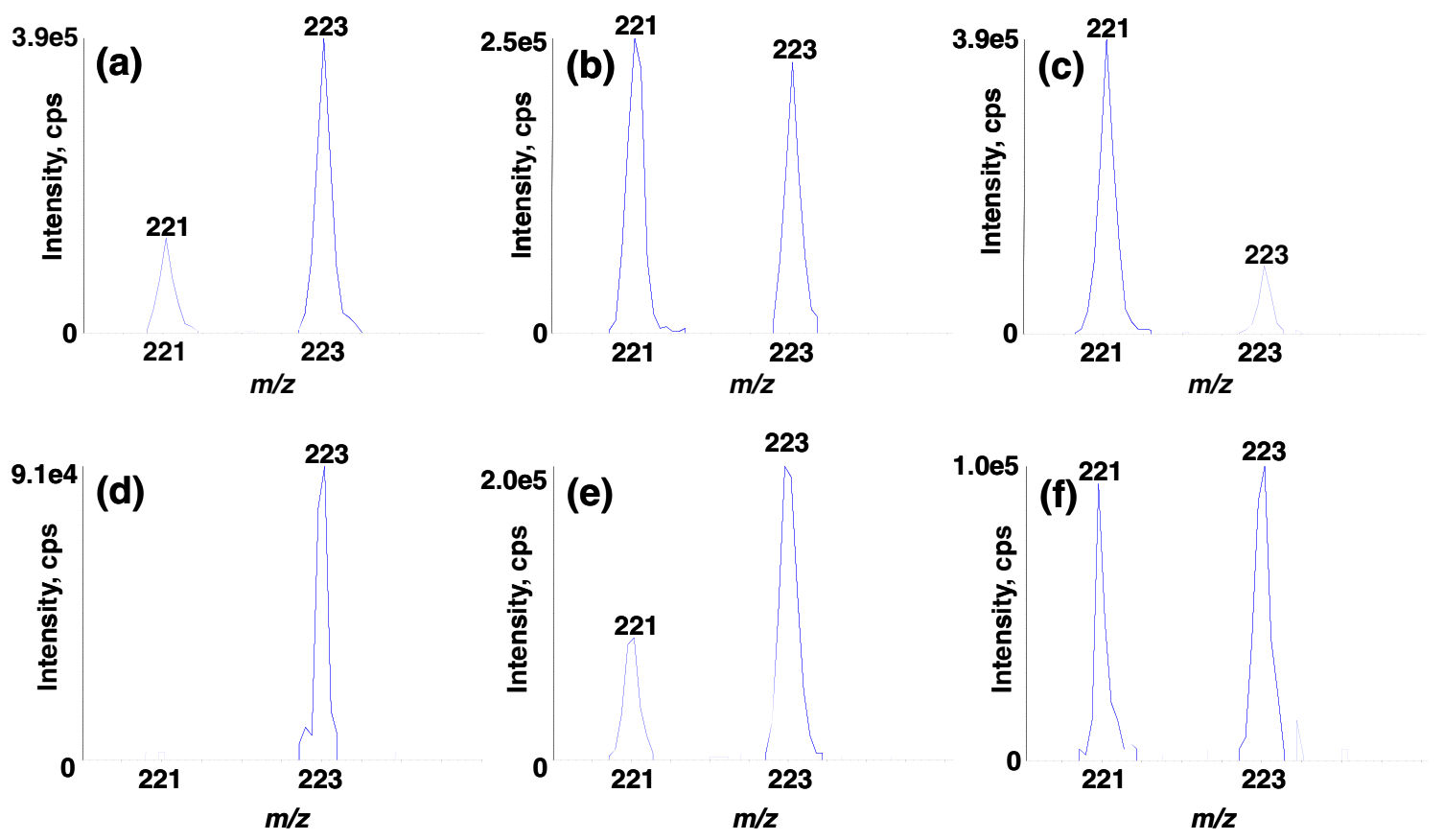

Figure 5. Isolation of $\mathrm{m} / \mathrm{z} 221$ and 223 ions derived from ${ }^{18} \mathrm{O}$-labeled $\beta$-D-Glcp-(1-3)-D-Glc under different collisional activation conditions. Beam-type CID: (a) $C E=5 \mathrm{~V}$, (b) $\mathrm{CE}=10 \mathrm{~V}$, (c) $\mathrm{CE}=15 \mathrm{~V}$. Ion trap $\mathrm{CID}$ at $\mathrm{q}=0.4, \mathrm{f}=119.248 \mathrm{kHz}$, excitation time $=50 \mathrm{~ms}$ : (d) $100 \mathrm{mV}_{p-p}$, (e) $250 \mathrm{mV}_{p-p}$, (f) $400 \mathrm{mV}_{p-p}$

generator was used for resonance excitation at $\mathrm{q}=0.4$. As shown in Figure 5d to $\mathrm{f}$, the ratio of $\mathrm{m} / \mathrm{z} 221$ to $\mathrm{m} / \mathrm{z} 223$ ions was increased from almost zero to about 1 as the activation amplitude was increased from $100 \mathrm{mV}_{p-p}$ to $400 \mathrm{mV}_{p-p}$ (activation time: $50 \mathrm{~ms}$ for all cases). Further increasing the activation amplitude resulted in a decrease in $\mathrm{m} / \mathrm{z} 221$ to 223 ratio as well as a huge ion loss.

The data in Figure 5 suggest that $\mathrm{m} / \mathrm{z} 221$ ions, which have the desired monosaccharide-GA structures, are generated more favorably under relatively high collision energy conditions in both beam-type and ion trap CID. Compared with ion trap CID, beam-type CID provided more abundant and higher relative intensities of the $\mathrm{m} / \mathrm{z} 221$ ions that were wanted for discrimination of the stereochemistry and anomeric configuration of the non-reducing sugar. Evidently, a higher activation energy is needed for the formation of these $m / z 221$ product ions, and the pathway to generate the glycosyl-GAs is favored when the internal energies of the molecular ions increase. In beam-type CID, much higher collision energies can be applied (typically more than $10 \mathrm{~V}$ ) as compared to ion trap CID (hundreds of $\mathrm{mV}$ ), which leads to a shift in the internal energy distribution of the molecular ions to the high energy direction [38]. It is interesting to point out that the glycosyl-glycolaldehyde product ions are virtually the only isomeric species generated under ion trap or low-energy beam-type CID of the 1-2 linked disaccharide anions [34]. Since much higher relative intensities of the glycosyl-glycolaldehyde product ions $(10 \%-40 \%$, normalized to the most abundant peak) can be formed from 1-2 linkages compared with that of $1-3$ linkages (typically $<1 \%$ relative intensity) under ion trap CID conditions, it is reasonable to conclude that the formation of these ions from 1-2 linkages needs less energy than required for their generation from 1-3 linkages. Therefore, the formation of the glycosyl-glycolaldehyde product ions is a much lower energy dissociation channel for 1-2 linked disaccharides but a fragmentation pathway for this isomeric species can only be promoted for 1-3 linked disaccharides when the collision energy is higher.

Given the high pressure in the collision cell ( $\sim 5$ mTorr), multiple collisions happen in beam-type CID, and the firstgeneration product ions may also be subjected to collisional activation once they are formed within the collision cell especially under higher CE conditions. In this sense, beamtype CID is less selective than ion trap CID, where fragment ions are not typically further activated. Indeed, $\mathrm{MS}^{3} \mathrm{CID}$ studies in the ion trap showed that many fragment ions, including $\mathrm{m} / \mathrm{z} 325,323,283,281,253$, and 251 generated $\mathrm{m} / \mathrm{z} 221$ ions, which might contribute to the observation of higher intensity $\mathrm{m} / z 221$ ions under beam-type CID due to secondary dissociation.

\section{Identification of the Non-Reducing Sugar and its Anomeric Configuration for 1-3 Linked Disaccharides}

Since relatively pure $\mathrm{m} / \mathrm{z} 221$ ions containing the intact nonreducing sugars could be formed using beam-type CID with high collision energies, it was possible to differentiate the stereochemistry and anomeric configuration of the non- 

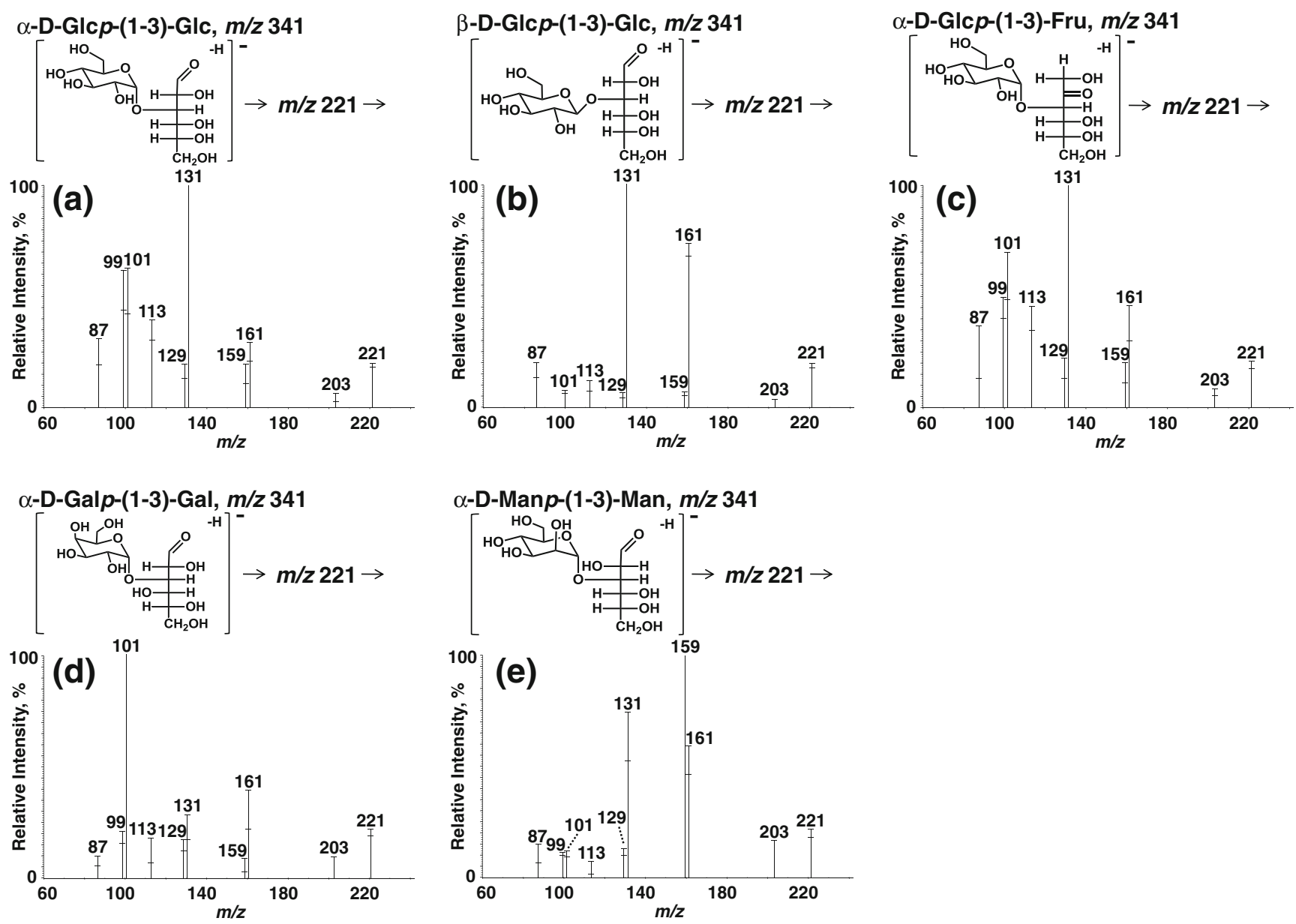

Figure 6. $\mathrm{MS}^{3} \mathrm{CID}$ of $\mathrm{m} / \mathrm{z} 221$ ions generated via using high $\mathrm{CE}$ (CE=13 to $22 \mathrm{~V}$ ) for the dissociation of deprotonated disaccharide ions $\left(m / z\right.$ 341). (a) $\alpha-D-G l c p-(1-3)-D-G l c, C E=15 \vee\left(M^{2}\right), A F 2=26\left(M^{3}\right)$, (b) $\beta-D-G l c p-(1-3)-D-G l c, C E=13 \vee$ $\left(\mathrm{MS}^{2}\right), \mathrm{AF} 2=30\left(\mathrm{MS}^{3}\right)$, (c) $\alpha-\mathrm{D}-\mathrm{Glcp}-(1-3)-\mathrm{D}-\mathrm{Fru}, \mathrm{CE}=18 \mathrm{~V}\left(\mathrm{MS}^{2}\right), \mathrm{AF} 2=25\left(\mathrm{MS}^{3}\right)$, (d) $\alpha-\mathrm{D}-\mathrm{Gal} p-(1-3)-\mathrm{D}-\mathrm{Gal}(3 \alpha-\mathrm{Gal}-\mathrm{Gal})$, $\mathrm{CE}=22 \mathrm{~V}\left(\mathrm{MS}^{2}\right), \mathrm{AF} 2=35\left(\mathrm{MS}^{3}\right)$, and (e) $\alpha-\mathrm{D}-\mathrm{Manp}-(1-3)-\mathrm{D}-\mathrm{Man}(3 \alpha-M a n-M a n), \mathrm{CE}=20 \mathrm{~V}\left(\mathrm{MS}^{2}\right), \mathrm{AF}^{2}=36\left(\mathrm{MS}^{3}\right)$. The error bars in the spectra show the standard deviation of peak intensities based on seven spectra collected over a one year period

reducing sugar in disaccharides without ${ }^{18} \mathrm{O}$-labeling. Figure 6 shows the $\mathrm{MS}^{3} \mathrm{CID}$ spectra of $\mathrm{m} / \mathrm{z} 221$ ions generated by beam-type CID with relatively high CE (13 to $22 \mathrm{~V}$ ) from five 1-3 linked disaccharides. Each spectrum was an average of seven spectra and the error bars indicate standard deviations of the peak intensities. The standard deviations were found to be higher $(0 \%-12 \%)$ for the disaccharide samples than those from standards $(0 \%-4 \%)$. This larger degree of spectral variation is likely contributed by the fluctuation in ion intensity of the low abundance $\mathrm{m} / \mathrm{z} 221$ isomers under slightly different instrument conditions, and these isomers fragment differently from the diagnostic and more abundant $\mathrm{m} / \mathrm{z} 221$ ions that have the monosaccharide-GA structures.

Note that $\alpha$-D-Glc $p$-(1-3)-D-Glc, $\alpha$-D-Glc $p$-(1-3)-D-Fru, and $\beta$-D-Glc $p$-(1-3)-Glc are disaccharide isomers containing a glucose as the non-reducing sugar; however, each has either a different anomeric configuration or reducing sugar. The characteristic fragmentation profile for disaccharides having glucose as the non-reducing sugar and an $\alpha$-anomeric configuration can be clearly identified for Figure 6a $(\alpha-\mathrm{D}-$ Glc $p-(1-3)-D-G l c)$ and Figure 6c ( $\alpha$-D-Glcp-(1-3)-D-Fru), which is distinct from the $\beta$-anomeric isomer as shown in Figure $6 \mathrm{~b}$ ( $\beta$-D-Glcp-(1-3)-D-Glc, compare all three to the synthetic standards shown in Figure $2 \mathrm{a}$ and $\mathrm{b}$ ). Figure $6 \mathrm{~d}$ shows the characteristic fragmentation profile for the $\mathrm{m} / \mathrm{z}$ 221 ion of disaccharides having galactose as the nonreducing sugar and having an $\alpha$-anomeric configuration (compare to Figure S3a, CID of $m / z 221$ from $\alpha$-D-Gal $p$-GA standard, Supporting Information). The $\mathrm{MS}^{3} \mathrm{CID}$ of $\alpha-\mathrm{D}$ Man $p$-(1-3)-Man (Figure 6e) was similar to that of the $\alpha-\mathrm{D}$ Manp-GA (Supporting Information, Figure S3b). It is also important to note that under low-energy dissociation conditions, the spectra of the $m / z 221$ product ions derived from the disaccharides $\alpha$-D-Glcp-(1-3)-D-Fru, $\alpha$-D-Gal $p$-(1-3)-D-Gal and $\alpha$-D-Manp-(1-3)-Man did not match those of their respective glycosyl-glycolaldehydes (Supporting Information, Figure S2b and Figure S3c and d). We conclude that this is due to the presence of alternate isomers, pos- 
Table 1. Spectral Similarity Scores for 1-3 Linked Disaccharides Versus Monosaccharide-GA Standards

\begin{tabular}{lcccc}
\hline Disaccharides & \multicolumn{3}{c}{ Synthesized Standards } \\
\cline { 2 - 5 } & $\alpha$-D-Glcp-GA & $\beta$-D-Glcp-GA & $\alpha$-D-Galp-GA & 0.8823 \\
$\alpha$-D-Glcp-(1-3)-Glc & $\mathbf{0 . 9 9 7 7}$ & 0.8845 & 0.7608 & 0.7968 \\
$\beta$-D-Glcp-(1-3)-Glc & 0.8572 & $\mathbf{0 . 9 8 4 0}$ & 0.9027 & 0.8568 \\
$\alpha$-D-Glcp-(1-3)-Fru & $\mathbf{0 . 9 9 3 0}$ & 0.8899 & 0.8045 \\
$\alpha$-D-Galp-(1-3)-Gal & 0.9178 & 0.7530 & 0.9838 & 0.6942 \\
$\alpha$-D-Manp-(1-3)-Man & 0.8461 & 0.8702 & $\mathbf{0 . 9 8 9 1}$ \\
\hline
\end{tabular}

sibly related in their origins to the hypothetical structures shown in Figure $4 \mathrm{~b}$ and $\mathrm{d}$ but having different reducing monosaccharides.

The methodology for assigning the stereochemistry and anomeric configuration for the non-reducing sugar unit within a disaccharide is based on the comparison of the CID patterns of $\mathrm{m} / \mathrm{z} 221$ ions to those of the synthetic monosaccharide-GA standards [33]. A high similarity between the compared spectra indicates a large likelihood of them sharing the same structure. Spectral similarity scores, which have been widely used in mass spectral library search for both small molecules [39], peptides [40-42], and oligosaccharides [43], were chosen to facilitate these comparisons. The spectral similarity scores were calculated between each of the averaged spectra in Figure 6 and the averaged spectra from the monosaccharide-GA standards based on the following equation [44],

Spectral similarity score $=\frac{\sum\left(k I_{m}^{1} I_{m}^{2}\right)^{1 / 2}}{\sum \frac{k I_{m}^{1}+I_{m}^{2}}{2}}$, and $\mathrm{k}=\frac{\sum I_{m}^{2}}{\sum I_{m}^{1}}$

where $I_{m}^{1}$ and $I_{m}^{2}$ are the normalized intensities of an ion at $m / z=\mathrm{m}$ for the two spectra. Note that the spectral similarity score always has a value between 0 and 1 . If two spectra are exactly the same, the spectral similarity score becomes 1 . In general, a large similarity score indicates close similarity between the two spectra and a large degree of structural similarity. As shown in Table 1, the spectral similarity scores between a standard and a disaccharide having the same stereochemistry and anomeric configuration for the non-reducing side were the highest scores, ranging between 0.9838 and 0.9977 . When a disaccharide's stereochemistry and anomeric configuration on the non-reducing side did not match with the standard, the spectral similarity score was significantly lower, between 0.6942 and 0.9178 . Clearly, by comparing the spectral similarity scores, assigning the stereochemistry and anomeric configuration for the nonreducing side of the 1-3 linked disaccharides could be achieved with high confidence. Note that this was only possible under high-energy beam-type CID conditions where the $m / z 221$ product anions containing the intact nonreducing sugars were optimally generated from precursor disaccharides.

\section{Conclusions}

Collisional activation of deprotonated 1-3 linked hexosecontaining disaccharides $(\mathrm{m} / \mathrm{z}$ 341) generated a low-abundance $\mathrm{m} / \mathrm{z} 221$ product ion. By ${ }^{18} \mathrm{O}$-labeling the reducing sugar carbonyl oxygen of these disaccharides, at least two structural isomers of the $\mathrm{m} / \mathrm{z} 221$ ion with the main portion derived from either side of the glycosidic linkage could be mass-discriminated ( $m / z 221$ vs. $m / z$ 223), which enabled the isomers to be isolated and independently studied. The $\mathrm{m} / \mathrm{z} 221$ isomer containing the intact non-reducing sugar attached in glycosidic linkage to a glycolaldehyde aglycon was found to be analytically useful, since CID of this species provided the structural information that identified the stereochemistry and anomeric configuration of the nonreducing sugar. No structural information could be obtained from $\mathrm{m} / \mathrm{z} 223$ isomer(s) to determine the stereochemistry of the non-reducing sugar or its anomeric configuration. The formation of the diagnostic $\mathrm{m} / \mathrm{z} 221$ isomer was found to be affected by CID conditions and was favored under higher energy beam-type CID. It was demonstrated that under optimized CID conditions, this structural isomer could be generated predominantly from five different 1-3 linked disaccharides without requiring ${ }^{18} \mathrm{O}$-labeling of the reducing sugar. Identification of the non-reducing sugar and the anomeric configuration, therefore, were achieved at a high confidence level by statistically comparing the CID data of $\mathrm{m} / \mathrm{z} 221$ ions generated from the disaccharide samples with those of the synthetic standards via spectral similarity scores. This study also demonstrated that beamtype CID was a more desirable activation method compared with ion trap CID to characterize disaccharides using the methodology based on the CID patterns of $\mathrm{m} / \mathrm{z} 221$ ions. This method now enables the anomeric configuration and stereochemistry of the $m / z 221$ ions derived from $1-2,-3,-4$, or -6 linked disaccharides to be assigned in the negative ion mode. This capability was afforded due to the specific arrangement of the triple quadrupole-linear ion trap instrument. It combined (1) selection of the precursor $(\mathrm{m} / \mathrm{z} 341)$ in the first quadrupole with (2) higher energy dissociation in the second quadrupole collision cell followed by (3) buildup of the desired low abundance $m / z 221$ product ion in the linear trap, all three of which were necessary to obtain these structural details for 1-3 linked disaccharides. 


\section{Acknowledgment}

B.B. acknowledges support from the National Science Foundation CHE-0137986.

\section{References}

1. Taylor, M.E., Drickamer, K.: Introduction to Glycobiology, 2nd edn. Oxford University Press, Oxford (2006)

2. Varki, A., Cummings, R.D., Esko, J.D., Freeze, H.H., Stanley, P., Bertozzi, C.R., Hart, G.W., Etzler, M.E.: Essentials of Glycobiology. Cold Spring Harbor Laboratory Press, Cold Spring Harbor (2009)

3. Bush, C.A., Martin-Pastor, M., Imberty, A.: Structure and conformation of complex carbohydrates of glycoproteins, glycolipids, and bacterial polysaccharides. Annu. Rev. Biophys. Biomolec. Struct. 28, 269-294 (1999)

4. Bendiak, B., Fang, T.T., Jones, D.N.: An effective strategy for structural elucidation of oligosaccharides through NMR spectroscopy combined with peracetylation using doubly $13 \mathrm{C}$-labeled acetyl groups. Can. J. Chem. 80, 1032-1050 (2002)

5. Armstrong, G.S., Mandelshtam, V.A., Shaka, A.J., Bendiak, B.: Rapid high-resolution four-dimensional NMR spectroscopy using the filter diagonalization method and its advantages for detailed structural elucidation of oligosaccharides. J. Magn. Reson. 173, 160-168 (2005)

6. Zaia, J.: Mass spectrometry of oligosaccharides. Mass Spectrom. Rev. 23, 161-227 (2004)

7. Fenn, J., Mann, M., Meng, C., Wong, S., Whitehouse, C.: Electrospray ionization for mass spectrometry of large biomolecules. Science $\mathbf{2 4 6}$ 64-71 (1989)

8. Reinhold, V.N., Reinhold, B.B., Costello, C.E.: Carbohydrate molecular weight profiling, sequence, linkage, and branching data: ES-MS and CID. Anal. Chem. 67, 1772-1784 (1995)

9. Karas, M., Bachmann, D., Bahr, U., Hillenkamp, F.: Matrix-assisted ultraviolet laser desorption of non-volatile compounds. Int. J. Mass Spectrom. 78, 53-68 (1987)

10. Tanaka, K., Waki, H., Ido, Y., Akita, S., Yoshida, Y., Yoshida, T., Matsuo, T.: Protein and polymer analyses up to $m / z 100,000$ by laser ionization time-of-flight mass spectrometry. Rapid Commun. Mass Spectrom. 2, 151-153 (1988)

11. Harvey, D.J.: Quantitative aspects of the matrix-assisted laser desorption mass spectrometry of complex oligosaccharides. Rapid Commun. Mass Spectrom. 7, 614-619 (1993)

12. Domon, B., Costello, C.E.: A systematic nomenclature for carbohydrate fragmentations in FAB-MS/MS spectra of glycoconjugates. Glycoconj. J. 5, 397-409 (1988)

13. Domon, B., Costello, C.E.: Structure elucidation of glycosphingolipids and gangliosides using high-performance tandem mass spectrometry. Biochemistry 27, 1534-1543 (1988)

14. Garozzo, D., Giuffrida, M., Impallomeni, G., Ballistreri, A., Montaudo, G.: Determination of linkage position and identification of the reducing end in linear oligosaccharides by negative ion fast atom bombardment mass spectrometry. Anal. Chem. 62, 279-286 (1990)

15. Dallinga, J.W., Heerma, W.: Reaction mechanism and fragment ion structure determination of deprotonated small oligosaccharides, studied by negative ion fast atom bombardment (tandem) mass spectrometry. Biol. Mass Spectrom. 20, 215-231 (1991)

16. Carroll, J.A., Ngoka, L., Beggs, C.G., Lebrilla, C.B.: Liquid secondary ion mass spectrometry/Fourier transform mass spectrometry of oligosaccharide anions. Anal. Chem. 65, 1582-1587 (1993)

17. Mulroney, B., Traeger, J.C., Stone, B.A.: Determination of both linkage position and anomeric configuration in underivatized glucopyranosyl disaccharides by electrospray mass spectrometry. J. Mass Spectrom. 30, 1277-1283 (1995)

18. Guan, B., Cole, R.B.: MALDI linear-field reflectron TOF post-source decay analysis of underivatized oligosaccharides: Determination of glycosidic linkages and anomeric configurations using anion attachment. J. Am. Soc. Mass Spectrom. 19, 1119-1131 (2008)

19. Jiang, Y., Cole, R.B.: Oligosaccharide analysis using anion attachment in negative mode electrospray mass spectrometry. J. Am. Soc. Mass Spectrom. 16, 60-70 (2005)

20. Firdoussi, A.E., Lafitte, M., Tortajada, J., Kone, O., Salpin, J.-Y.: Characterization of the glycosidic linkage of underivatized disaccharides by interaction with $\mathrm{Pb}^{2+}$ ions. J. Mass Spectrom. 42, 999-1011 (2007)
21. Staempfli, A., Zhou, Z., Leary, J.A.: Gas-phase dissociation mechanisms of dilithiated disaccharides: Tandem mass spectrometry and semiempirical calculations. J. Org. Chem. 57, 3590-3594 (1992)

22. Laine, R.A., Pamidimukkala, K.M., French, A.D., Hall, R.W., Abbas, S.A., Jain, R.K., Matta, K.L.: Linkage position in oligosaccharides by fast atom bombardment ionization, collision-activated dissociation, tandem mass spectrometry and molecular modeling. L-Fucosyl $\mathrm{p}_{\mathrm{p}}$ $(\mapsto 1 \rightarrow \mathrm{X})$-D-N-acetyl-D-glucosaminyl $-(\beta 1 \rightarrow 3)$-D-galactosyl $-(\beta 1-\mathrm{O}$ methyl) where $\mathrm{X}=3,4$, or 6. J. Am. Chem. Soc. 110, 6931-6939 (1988)

23. Hofmeister, G.E., Zhou, Z., Leary, J.A.: Linkage position determination in lithium-cationized disaccharides: tandem mass spectrometry and semiempirical calculations. J. Am. Chem. Soc. 113, 5964-5970 (1991)

24. Asam, M.R., Glish, G.L.: Tandem mass spectrometry of alkali cationized polysaccharides in a quadrupole ion trap. J. Am. Soc. Mass Spectrom. 8, 987-995 (1997)

25. Polfer, N.C., Valle, J.J., Moore, D.T., Oomens, J., Eyler, J.R., Bendiak, B.: Differentiation of isomers by wavelength-tunable infrared multiplephoton dissociation-mass spectrometry: Application to glucose-containing disaccharides. Anal. Chem. 78, 670-679 (2005)

26. Simoes, J., Domingues, P., Reis, A., Nunes, F.M., Coimbra, M.A., Domingues, M.R.: Identification of anomeric configuration of underivatized reducing glucopyranosyl-glucose disaccharides by tandem mass spectrometry and multivariate analysis. Anal. Chem. 79, 58965905 (2007)

27. Zhang, H., Brokman, S.M., Fang, N., Pohl, N.L., Yeung, E.S.: Linkage position and residue identification of disaccharides by tandem mass spectrometry and linear discriminant analysis. Rapid Commun. Mass Spectrom. 22, 1579-1586 (2008)

28. Mendonca, S., Cole, R., Zhu, J., Cai, Y., French, A., Johnson, G., Laine, R.: Incremented alkyl derivatives enhance collision induced glycosidic bond cleavage in mass spectrometry of disaccharides. $\mathrm{J}$. Am. Soc. Mass Spectrom. 14, 63-78 (2003)

29. Gaucher, S.P., Leary, J.A.: Stereochemical differentiation of mannose, glucose, galactose, and talose using zinc(II) diethylenetriamine and ESIion trap mass spectrometry. Anal. Chem. 70, 3009-3014 (1998)

30. Desaire, H., Leary, J.A.: Differentiation of diastereomeric $N$-acetylhexosamine monosaccharides using ion trap tandem mass spectrometry. Anal. Chem. 71, 1997-2002 (1999)

31. Mueller, D.R., Domon, B.M., Blum, W., Raschdorf, F., Richter, W.J.: Direct stereochemical assignment of sugar subunits in naturally occurring glycosides by low energy collision induced dissociation. Application to papulacandin antibiotics. Biol. Mass Spectrom. 15, 441446 (1988)

32. Domon, B., Muller, D.R., Richter, W.J.: Determination of interglycosidic linkages in disaccharides by high performance tandem mass spectrometry. Int. J. Mass Spectrom. Ion Process. 100, 301-311 (1990)

33. Fang, T.T., Bendiak, B.: The stereochemical dependence of unimolecular dissociation of monosaccharide-glycolaldehyde anions in the gas phase: A basis for assignment of the stereochemistry and anomeric configuration of monosaccharides in oligosaccharides by mass spectrometry via a key discriminatory product ion of disaccharide fragmentation, $m / z$ 221. J. Am. Chem. Soc. 129, 9721-9736 (2007)

34. Fang, T.T., Zirrolli, J., Bendiak, B.: Differentiation of the anomeric configuration and ring form of glucosyl-glycolaldehyde anions in the gas phase by mass spectrometry: isomeric discrimination between $\mathrm{m} / \mathrm{z}$ 221 anions derived from disaccharides and chemical synthesis of $\mathrm{m} / \mathrm{z}$ 221 standards. Carbohydr. Res. 342, 217-235 (2007)

35. Brown, D.J., Stefan, S.E., Berden, G., Steill, J.D., Oomens, J., Eyler, J. R., Bendiak, B.: Direct evidence for the ring opening of monosaccharide anions in the gas phase: photodissociation of aldohexoses and aldohexoses derived from disaccharides using variable-wavelength infrared irradiation in the carbonyl stretch region. Carbohydr. Res. 346, 2469-2481 (2011)

36. Carroll, J.A., Ngoka, L., Beggs, C.G., Lebrilla, C.B.: Liquid secondary ion mass spectrometry/Fourier transform mass spectrometry of oligosaccharide anions. Anal. Chem. 65, 1582-1587 (1993)

37. Bendiak, B., Fang, T.T.: Assignment of the stereochemistry and anomeric configuration of structurally informative product ions derived from disaccharides: infrared photodissociation of glycosyl-glycolaldehydes in the negative ion mode. Carbohydr. Res. 345, 2390-2400 (2010)

38. Wells, J.M., McLuckey, S.A. Collision-Induced Dissociation (CID) of Peptides and Proteins. In: Biol. Mass Spectrom. Burlingame, A.L. (ed.) Academic Press, Amsterdam, pp. 148-185 (2005) 
39. Stein, S., Scott, D.: Optimization and testing of mass spectral library search algorithms for compound identification. J. Am. Soc. Mass Spectrom. 5, 859-866 (1994)

40. Frewen, B.E., Merrihew, G.E., Wu, C.C., Noble, W.S., MacCoss, M.J.: Analysis of peptide MS/MS spectra from large-scale proteomics experiments using spectrum libraries. Anal. Chem. 78, 5678-5684 (2006)

41. Lam, H., Deutsch, E.W., Eddes, J.S., Eng, J.K., King, N., Stein, S.E., Aebersold, R.: Development and validation of a spectral library searching method for peptide identification from MS/MS. Proteomics 7, 655-667 (2007)
42. Lam, H., Deutsch, E.W., Eddes, J.S., Eng, J.K., Stein, S.E., Aebersold, R.: Building consensus spectral libraries for peptide identification in proteomics. Nat. Methods 5, 873-875 (2008)

43. Kameyama, A., Kikuchi, N., Nakaya, S., Ito, H., Sato, T., Shikanai, T., Takahashi, Y., Takahashi, K., Narimatsu, H.: A strategy for identification of oligosaccharide structures using observational multistage mass spectral library. Anal. Chem. 77, 4719-4725 (2005)

44. Zhang, Z.: Prediction of low-energy collision-induced dissociation spectra of peptides. Anal. Chem. 76, 3908-3922 (2004) 